\title{
Electrochemical Synthesis of Silver-Based Antiseptic
}

\author{
Shtefan V Viktoriia* and Manuilov M Andrii \\ Department of Technical Electrochemistry, Ukraine
}

*Corresponding author: Shtefan VViktoriia, Department of Technical Electrochemistry, Ukraine,

Submission: 侮June 06, 2018; Published: 非 July 11, 2018

\begin{abstract}
The increase of the number of strains resistant to antibiotics and other antimicrobial agents is steadily increasing [1]. The emergence of multidrugresistant strains poses a serious threat to public health, and the search for ways to reduce such risks is an urgent task. This review is devoted to a comprehensive study of an antiseptic based on silver ions stabilized in the citrate complex.
\end{abstract}

Keywords: Antiseptic; Silver; Citrate; Voltammetry studies; ATCC

\section{Introduction}

It's known that silver and its compounds [2] are antimicrobial and bacteriostatic agents. The results of the investigations $[3,4]$ showed that silver solutions obtained by the electrochemical method have the strong antiseptic activity. It was found that such solutions are not inferior, by their antiseptic activity, to the $68 \%$ isopropyl alcohol [4]. However, the duration of the antimicrobial action of these solutions is limited and there is a need to prolonged the antiseptic effect. Most of the solutions of silver, stabilized with citrate, contain not less than $8-10 \%$ citric acid or salts of this acid. But its need to mark, that the citrate acid and salts of this acid are substratum for microorganisms. This becomes a serious problem if it isn't possible to conduct regular disinfection. This study offers a solution to this problem.

\section{Materials \& Methods}

A comprehensive study included voltammetry studies [5], atomic spectroscopy, and microbiological studies. To record the data, the potentiostat-galvanostat IPC Pro [6] and the atomicabsorption spectrometer MGA-915M were used. The antiseptic prepared by electrochemical dissolution of an electrode from silver $925^{\circ}$ in an aqueous solution containing $0.5 \%$ citric acid and $0.5 \%$ sodium citrate. For the preparation of solution chemically pure reagents and distilled water were used. Microbiological testing was carried out on test strains from the American Type Culture Collection: E. Coli ATCC 25922, Staphylococcus Aureus ATCC 25923, Candida Albicans ATCC 885-653 and Proteus Vulgaris ATCC 4636. The control and initial dose for all test strains was $10^{8}-10^{9} \mathrm{CFU} / \mathrm{ml}$ (ln $\mathrm{CFU} / \mathrm{ml}$ is $20,72-18,42$ ).

\section{Results \& Discussion}

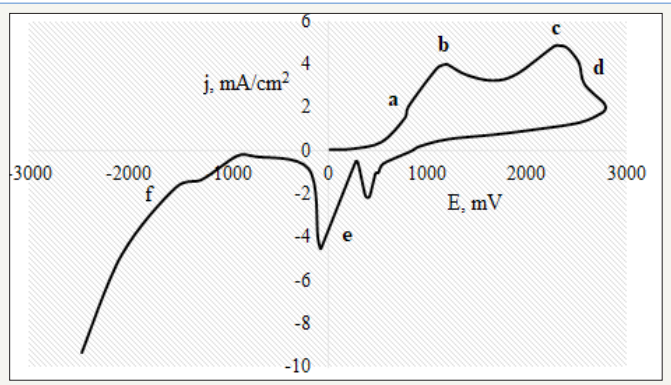

Figure 1: Voltammetry graph of silver in an aqueous solution containing $0.5 \%$ citric acid and $0.5 \%$ sodium citrate.

a. Region of active dissolution;

b. Region of the limiting current density;

c. Region of oxidation of citrates;

d. Region of passivation of the surface of oxidation products of citrates;

e. Area of two-step reduction of silver cations;

f. Region of hydrogen evolution. 


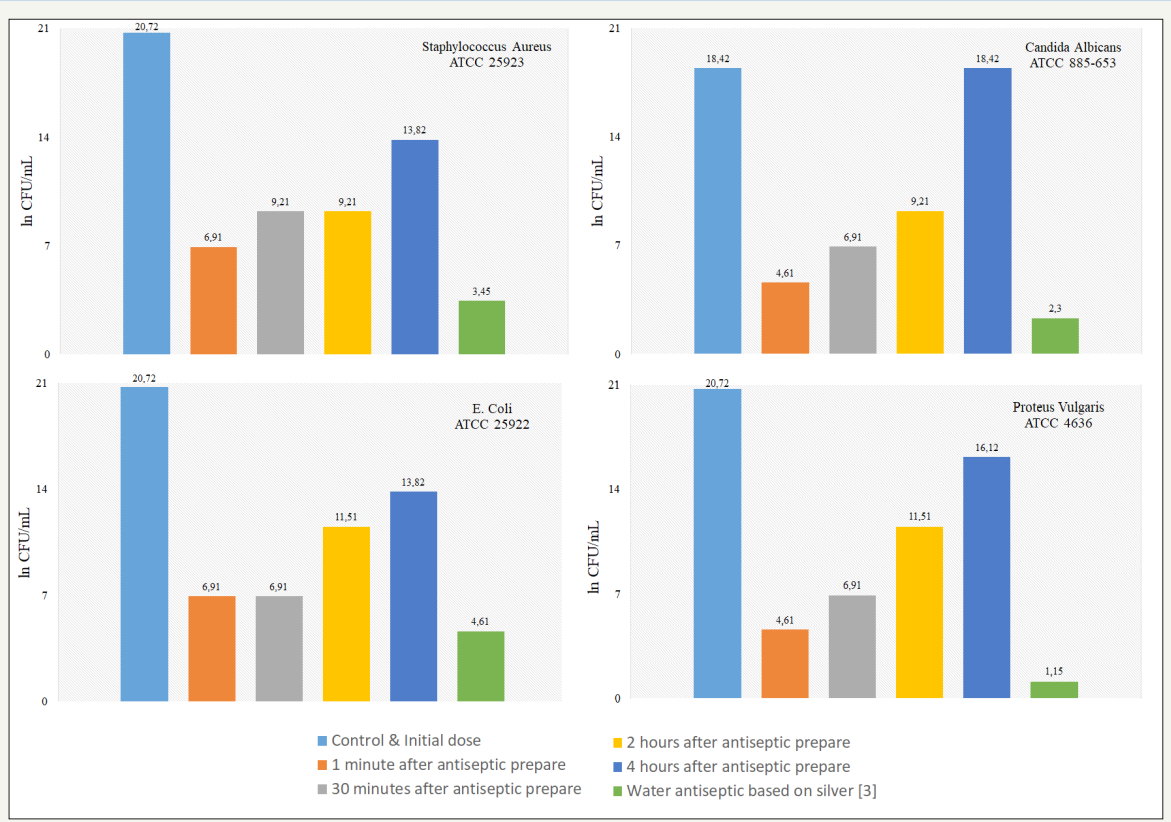

Figure 2: Antimicrobial effectiveness of antiseptic against test strains.

The results of voltammetry studies are shown in Figure 1. The analysis of the voltammetry graph showed that the working potential range is $650 \ldots 1100 \mathrm{mV}$ and further anodic polarization leads to irreversible oxidation of the solution components. The operating current density is in the range $0.5 . . .4 \mathrm{~mA} / \mathrm{cm}^{2}[7-10]$. These data indicate that electrochemical generation of antiseptic is an energy-efficient process that does not require significant energy expenditure. The energy intensity of synthesis of 1 liter of antiseptic doesn't exceed 10-12W. The results of microbiological studies are shown in Figure 2.

Microbiological control showed that the synthesized antiseptic has a pronounced antimicrobial activity against gram-positive and gram-negative bacteria, as well as against fungi strain Candida Albicans. The maximum antimicrobial effectiveness is manifested for 30 minutes, then decreases to a minimum within 3.5 hours. Analytical analysis on an atomic-adsorption spectrometer showed that the content of silver in the antiseptic agent is in the range $0.0245-0.0272 \mathrm{mg} / \mathrm{dm}^{3}$. This is $72.8 \%$ lower than the WHO recommendation [11] for the maintenance of silver in drinking water.

\section{Conclusion}

The synthesized antiseptic has a pronounced antimicrobial and fungicidal effect. The content of silver in the antiseptic is not toxic or dangerous to humans; all components of the antiseptic are ecology friendly. The electrochemical method of synthesizing antiseptics is completely controllable by controlling the current and voltage.

\section{References}

1. Mitscher LA, Pillai SP, Gentry EJ, Shankel DM (1999) Multiple drug resistance. Med Research Rev 19(6): 477-496.
2. Fewtrell L (2014) Silver: water disinfection and toxicity. Aberystwyth University, Aberystwyth, UK, p. 53.

3. Manuilov AM, Martynov AV (2017) The analysis of the threat of reusing pet bottles for the storage of drinking water. Annals of Mechnicov Institute 4: 26-32.

4. Manuilov AM, Martynov AV (2018) Antiseptic spray based on stabilized silver particles: an analysis of antiseptic properties and comprehensive comparison. Annals of Mechnicov Institute 1: 21-27.

5. Shtefan VV, Smirnova AY (2017) Oxidation of titanium in Zr-and Mocontaining solutions. Protection of Metals and Physical Chemistry of Surfaces 53(2): 322-328.

6. Pospelov AP, Ved MV, Sakhnenko ND, Alexandrov YL, Shtefan VV, et al. (2002) High-conductivity organic metals as electrode materials. Materials Science 20(3): 65-72.

7. Nenastina T, Bairachnaya T, Ved M, Shtefan V, Sakhnenko N (2007) Electrochemical synthesis of catalytic active alloys. Functional materials 14(3): 395.

8. Shtefan VV, Smirnova AY (2013) Electrochemical formation of ceriumcontaining oxide coatings on titanium. Russian Journal of Applied Chemistry 86(12): 1842-1846.

9. Shtefan VV, Smirnova AY (2015) Synthesis of Ce-, Zr-, and Cu-containing oxide coatings on titanium using microarc oxidation. Russian Journal of Electrochemistry 51(12): 1168-1175.

10. Shtefan VV, Epifanova AS, Koval'ova AA, Bairachnyi BI (2017) Electrolytic deposition of highly hard coatings of a cobalt-molybdenum alloy. Materials Science 53(1): 47-54.

11. WHO (2011) Guidelines for drinking-water quality. ( $4^{\text {th }}$ edn), WHO Library Cataloguing-in-Publication Data, Switzerland, p. 415 
Creative Commons Attribution 4.0 International License

For possible submissions Click Here

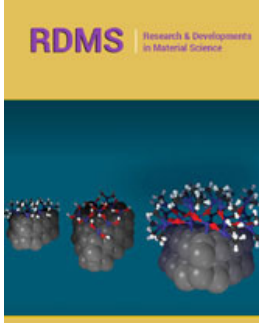

\section{Research \& Development in Material Science}

\section{Benefits of Publishing with us}

- High-level peer review and editorial services

- Freely accessible online immediately upon publication

- Authors retain the copyright to their work

- Licensing it under a Creative Commons license

- Visibility through different online platforms 